\title{
Mating behaviour of a bull and its relationship with serum LH levels in a group of oestrous cows
}

\author{
M. Umezu, J. Masaki, H. Sasada and M. Ohta \\ Department of Animal Science, Faculty of Agriculture, Tohoku University, Sendai-shi, and \\ *Tohoku University Farm, Narugomachi, Miyagiken, Japan
}

\begin{abstract}
Summary. A PGF-2 $\alpha$ analogue (cloprostenol) was injected into 9 cows to synchronize oestrus. The cows were placed with or without a bull in a free-stall in groups of 3 at $46 \mathrm{~h}$ after the injection. Sexual behaviour was observed and serum $\mathrm{LH}$ concentrations were measured during the next $34 \mathrm{~h}$.

The bull ejaculated with the cows in regular sequence and did not return to cows after an ejaculatory series was completed. The mating behaviour of the bull was closely related to the $\mathrm{LH}$ surge of the cows.
\end{abstract}

\section{Introduction}

Mating activity of a beef bull to a group of oestrous heifers has been observed after synchronization of oestrus by means of an analogue of prostaglandin (PG) F-2 $\alpha$ (Ohta, Masaki, Sasada, Wada \& Nihei, 1979; Sasada, Masaki, Wada, Ohta \& Nihei, 1979; Masaki, Sasada \& Ohta, 1980). In such an environment the bull behaved apparently according to a rule by which he chose a partner heifer one by one. In laboratory animals, sexual receptivity depends greatly on the hormonal state of the female (Moss \& McCann, 1973; Pfaff, 1973; reviewed by Kow, Malsbury \& Pfaff, 1975; Fedder \& Marrone, 1977). In cattle, however, little is known about whether the mating behaviour of the bull is determined by the alteration of hormonal status in the cow. The present study was therefore undertaken to examine the relationship of mating behaviour of a bull with the concentrations of serum LH in oestrous cows.

\section{Materials and Methods}

Three groups each of 3 cows (Japanese Shorthorn and Japanese Black) were injected intramuscularly with $500 \mu \mathrm{g}$ cloprostenol during the luteal phase, 8-15 days after ovulation was detected by rectal palpation. At 10:00 h, $46 \mathrm{~h}$ after PG treatment, the cows were placed in a free-stall measuring $7.5 \times 10 \mathrm{~m}$ for the observation of sexual behaviour. The cattle received food and water ad libitum during the observation time of $34 \mathrm{~h}$.

Experiment 1 was carried out in December with two of the groups (A and B), one of which (Group B) contained a Japanese Black bull of 2 years of age and no experience of pasture mating. The behaviour of the bull and its influence on the behaviour of cows were observed. Experiment 2 was carried out in March with the 3rd group (S) which contained a Japanese Shorthorn bull, 4.5 years old but with mating experience. The behaviours recorded were the mounts made by and received by the cow and ejaculation of the bull. Blood samples were taken from the jugular vein of cows every $4 \mathrm{~h}$ during the period $48-76 \mathrm{~h}$ after PG injection. After clotting in a refrigerator and centrifugation, the serum was stored at $-70^{\circ} \mathrm{C}$ until used for $\mathrm{LH}$ estimation. The cows were checked for ovulation by rectal palpation every $4 \mathrm{~h}$ until $24 \mathrm{~h}$ and for pregnancy 45 days after the end of observation. 
LH concentrations were measured by the double-antibody radioimmunoassay method of Niswender, Reichert, Midgley \& Nalbandov (1969). The antibody (GDN No. 15) was kindly supplied by Dr G. D. Niswender, Colorado State University, Fort Collins, Colorado, U.S.A. NIH-LER-1702 and NIH-LH-B 10 were kindly supplied by Dr L. E. Reichert, Emory University, Georgia, Atlanta, U.S.A., and used for iodination and as the reference standard, respectively. The volume of serum for the assay was $0.5 \mathrm{ml}$ per test-tube with duplicates for each sample. The mean value was recorded. The sensitivity of the $\mathrm{LH}$ assay was $0.3 \mathrm{ng} / \mathrm{ml}$. The interand intra-assay coefficients of variation were 7.7 and $6.4 \%$, respectively.

\section{Results}

Cow-to-cow mount-receiving behaviour. Two cows in Group A started mount-receiving behaviour 3.2 and $4.4 \mathrm{~h}$ respectively after introduction into the free-stall, and continued the behaviour for 17-18 h (Text-fig. 1). The third cow, which did not exhibit any other oestrous signs, displayed little of this behaviour. In Group B the cow-to-cow behaviour began in two cows at 4.0 and $12.7 \mathrm{~h}$ respectively after introduction of the bull but the mean frequency of the behaviour was extremely low (Text-fig. 1). The third cow (No. 4) in this group showed no activity of this kind. In Group $S$ the oestrous behaviour occurred $6.5,15.1$ and $20.0 \mathrm{~h}$ respectively after introduction and the mean frequency was again less than that of the cows in Group A.

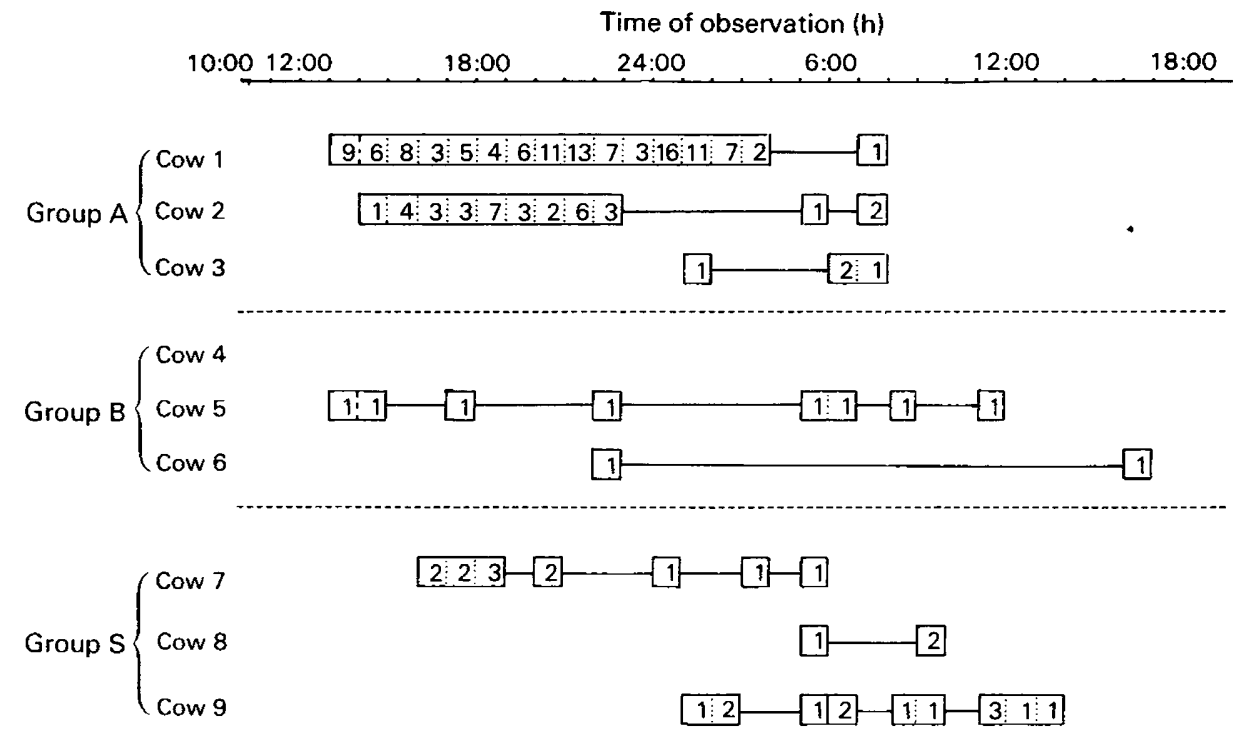

Text-fig. 1. Occurrence of mount-receiving behaviour amongst cows observed for $34 \mathrm{~h}$ starting $46 \mathrm{~h}$ after an injection of PGF-2 $\alpha$ analogue to synchronize oestrus. The numerical values indicate the frequency of the behaviour per hour.

Mounting and ejaculation behaviour of bulls. The bull in Group B mounted the 3 cows several times within $4.5 \mathrm{~h}$ after introduction (Text-fig. 2). Ejaculation with the cows occurred over $8.4,8.9$ and $9.6 \mathrm{~h}$, respectively. The bull did not return to a cow with which a series of ejaculations had been completed. The bull in Group S mounted and ejaculated with 2 of the cows for 10.4 and 9.9 h, respectively. The 3 rd cow (No. 9) was ignored, although she received mounts from the other cows (Text-fig. 1) 
Time of observation (h)
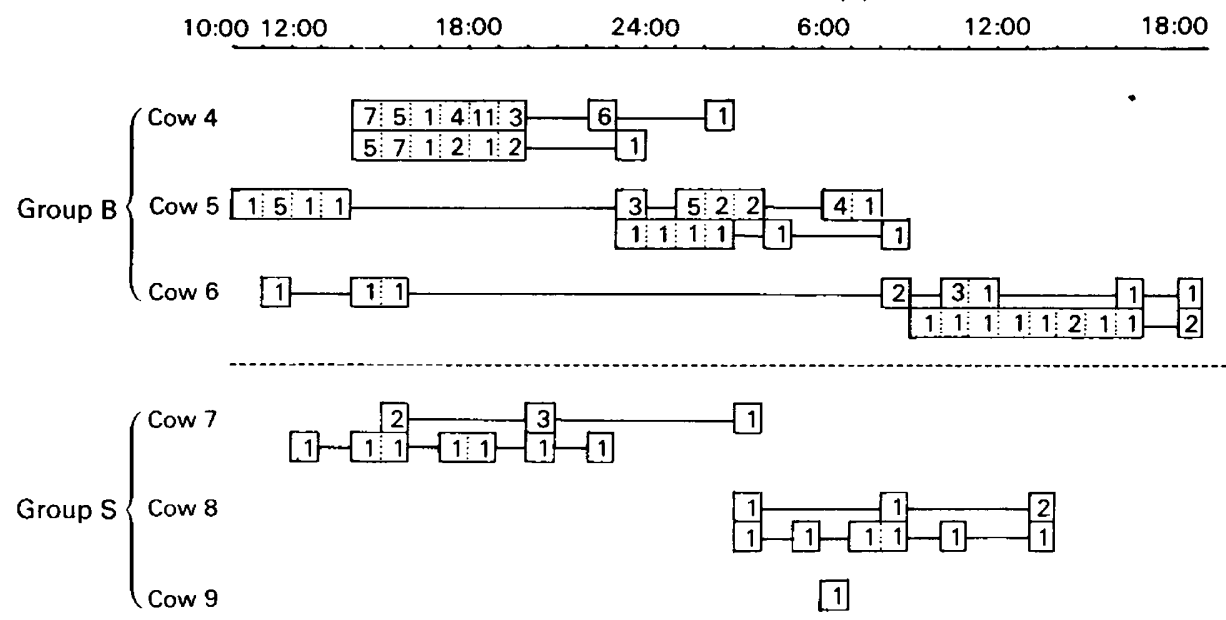

Text-fig. 2. Occurrence of mounting (upper row) and ejaculatory (lower row) behaviour of the bulls in Groups B and S. The numerical values indicate the frequency of the behaviour per hour.

Ovulation time after PG injection. The ovulation time was $94 \pm 3 \mathrm{~h}$ (mean \pm s.d.) after the PG injection. Neither luteal regression nor ovulation was detected in Cow 3 in Group A.

Patterns of LH secretion. The LH surge occurred for 8-12 h with a peak at 52-72 h after PG injection in 7 of the 9 cows. Cows 3 and 9 did not show any significant release of LH. The LH surges clearly coincided with the ejaculatory patterns of the bulls in Groups B and S (Text-fig. 3).

Reproductive record. Of the 9 cows, 7 ovulated and 5 of the 6 cows exposed to a bull conceived.

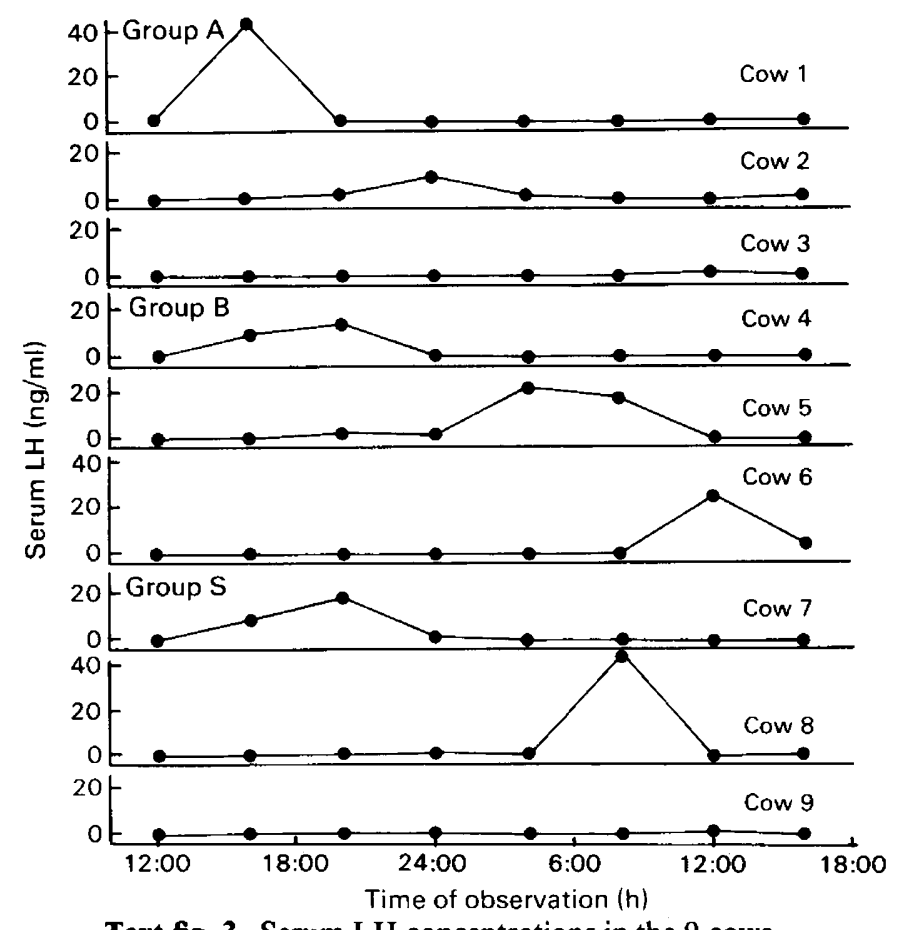

Text-fig. 3. Serum LH concentrations in the 9 cows. 


\section{Discussion}

The occurrence of cow-to-cow mount-receiving behaviour was clearly less in the groups consisting of a bull and 3 cows, compared with that in the groups without a bull. This result differed from that of previous studies (Ohta et al., 1979; Sasada et al., 1979; Masaki et al., 1980), in which the bull was placed with $7-15$ oestrous heifers. These data indicate that cow-to-cow behaviour may be influenced by the size of the group and the presence and experience of a bull. The bulls used in the present study were of different ages and experience and the young inexperienced bull mounted more frequently and vigorously. The results of the present study confirmed that the bulls rarely returned to a cow after a completed series of ejaculations, The mating activity of the bull and the LH surge in the cows were almost perfectly synchronized. It is unlikely that the mating stimulus resulted in the LH surge in the cows, because similar changes in LH concentrations occurred in 2 of the cows in Group A without a bull. The bull did not ejaculate or mount a cow in which there was no LH surge.

The reason why mating behaviour of the bull is synchronized to the LH release of cows is not clear. Alexander, Signoret \& Hafez (1980) considered that the primary factor prescribing the sexual behaviour of the male exists exclusively in the female. In female rats LH-RH (Moss \& McCann, 1973; Pfaff, 1973) and/or progesterone act(s) (Kow et al., 1975; Fedder \& Marrone, 1977) directly on the brain to induce lordosis under the influence of increased levels of blood oestrogen. When PFG-2 $\alpha$ or an analogue is injected into cows, blood progesterone decreases with the regression of the corpus luteum, followed by an increase of oestrogen secretion from the follicle and induction of oestrus (Louis, Hafs \& Seguin, 1973; Chenault, Thatcher, Karla, Abrams \& Wilcox, 1976). If this also occurs in cattle, oestrogen may act on the central nervous system to stimulate LH-RH secretion as the primary factor leading to receptivity to the bull. However, there is little information on the effect of LH-RH on the receptivity in cattle.

We thank Mr Akira Nihei for technical assistance and to Sumitomo Chemical Co. for providing the cloprostenol from I.C.I.

\section{References}

Alexander, G., Signoret, J.P. \& Hafez, E.S.E. (1980) Sexual, maternal and neonatal behavior. In Reproduction in Farm Animals, 4th edn, pp. 304-322. Ed. E. S. E. Hafez. Lea \& Febiger, Philadelphia.

Chenault, J.R., Thatcher, W.W., Karla, P.S., Abrams, R.M. \& Wilcox, C.J. (1976) Plasma progestins, estradiol, and luteinizing hormone following prostaglandin F-2 $\alpha$ injection. J. Dairy Sci. 59, 13421346.

Fedder, H.H. \& Marrone, B.L. (1977) Progesterone: its role in the central nervous system as a facilitator and inhibitor of sexual behavior and gonadotropin release. Ann. N. Y. Acad. Sci. 286, 331-354.

Kow, L.M., Malsbury, C.W. \& Pfafi, D.W. (1975) Effects of progesterone on female reproductive behavior in rats: possible modes of action and role in behavioral sex difference. In Reproductive Behavior, pp. 179-210. Eds W. Montagna \& W. A. Sadler. Plenum, New York.

Louis, T.M., Hafs, H.D. \& Seguin, B.E. (1973) Progesterone, LH, estrus and ovulation after prostaglandin F-2 $\alpha$ in heifers. Proc. Soc. exp. Biol. Med. 143, 152-155.
Masaki, J., Sasada, H. \& Ohta, M. (1980) Serving activity of a beef bull to a group of oestrussynchronized cows. Proc. 9th Int. Congr. Anim. Reprod. \& A. I., Madrid, p. 12, Abstr.

Moss, R.L. \& McCann, S.M. (1973) Induction of mating behavior in rats by luteinizing hormone-releasing factor. Science, N.Y. 181, 171-179.

Niswender, G.D., Reichert, L.E., Jr, Midgley, A.R., Jr \& Nalbandov, A.V. (1969) Radioimmunoassay for bovine and ovine luteinizing hormone. Endocrinology 84, 1166-1173.

Ohta, M., Masaki, J., Sasada, H., Wada, R. \& Nihei, A. (1979) Serving activity of a beef bull to heifers in which estrus was synchronized. Jap. J. Zootech. Sci. 50, 235-238.

Pfaff, D.W. (1973) Luteinizing hormone-releasing factor potentiates lordosis behavior in hypophysectomized ovariectomized female rats. Science, N.Y. 182, $1148-1149$.

Sasada, H., Masaki, J., Wada, R., Ohta, M. \& Nihei, A. (1979) Serving activity of a beef bull to a group of fifteen heifers treated with PGF- $2 \alpha$ analogue. Jap. $J$. Anim. Reprod. 25, 198-202. 